\title{
Bowenoid Actinic Keratosis and Bowen's Disease Treated Successfully with Ingenol Mebutate
}

\author{
Mosab T. Mohanna ${ }^{a, b}$ Günther F.L. Hofbauer ${ }^{a}$ \\ ${ }^{a}$ Department of Dermatology, University Hospital Zurich, Zurich, Switzerland; ${ }^{b}$ Department of Dermatology, \\ Taibah University, Medina, Saudi Arabia
}

\section{Key Words}

Actinic keratosis · Bowen's disease · Ingenol mebutate

\begin{abstract}
Ingenol mebutate (IM) is a topical pharmacotherapy approved in Switzerland since 2012 for treating non-hypertrophic, non-hyperkeratotic actinic keratosis (AK). We report 2 cases with off-label use of IM. The first case of bowenoid AK was treated with $150 \mu \mathrm{g}$ IM for 3 consecutive days with an almost complete clinical remission of the lesion. The second case of Bowen's disease was treated with 500 Mg IM for 2 consecutive days leading to complete clinical remission.
\end{abstract}

(c) 2016 S. Karger AG, Base

\section{Case Report}

We report on the use of ingenol mebutate (IM) in bowenoid actinic keratosis (AK) and Bowen's disease (BD), both of which are beyond the registered indication of non-hypertrophic, non-hyperplastic AK and thus constitute off-label treatment.

Case One

The first case was a 78-year-old female patient referred to our clinic for a histologically confirmed bowenoid AK at the lateral commissure of her lower left eyelid. Various topical modalities including imiquimod (IQ) and photodynamic therapy (PDT) had been performed with varying success. Due to the size and location of the lesion, the service of plastic surgery declined total excision, which corresponded to patient preference as well. Based on a phase I/II clinical study using Euphorbia peplus sap with the active ingredient IM in treating intra-epidermal carcinomas (IECs) successfully in a limited number of patients [1], we decided to apply $150 \mu \mathrm{g}$ IM for 3 consecutive days as off-label treatment for this bowenoid AK. A pronounced local skin reaction around the left eye with erythema and erosion was seen, with disappearance of pigmentation and remaining erythema without scaling at 2 weeks of follow-up. Dermatoscopically, focal peppering with almost complete clinical regression of the pigmentation was seen at 6-month follow-up with good cosmetic outcome (fig. 1).

\section{Case Two}

The second case was a 73-year-old male patient in regular follow-up in our clinic for a history of dermatitis who presented with a new skin lesion on the left dorsum of the hand. Clinically, a brown-red plaque of $2 \mathrm{~cm}$ diameter was observed. Dermatoscopically, a pseudo-network, superficial scales and dotted vessels were noted. Based on our clinical diagnosis of BD and on our successful treatment of the first case with bowenoid AK as well as the patient's desire of a simplified way of treatment, we started an off-label treatment with $500 \mu \mathrm{g}$ IM for 2 consecutive days, leading to crust formation, which resolved after 1 week with complete clinical remission at 6 weeks' follow-up (fig. 2).

\section{Discussion}

$\mathrm{BD}$ is a form of squamous cell carcinoma in-situ, which may develop to invasive SCC in 3-26\% cases when left untreated [2]. Surgical excision, laser destruction, electroco-

\section{KARGER}

E-Mail karger@karger.com

www.karger.com/drm
C 2016 S. Karger AG, Base

$1018-8665 / 16 / 2327-0014 \$ 39.50 / 0$
Mosab T. Mohanna, MD

Department of Dermatology, University Hospital Zurich

Gloriastrasse 31

CH-8091 Zurich (Switzerland)

E-Mail mohanna.mosabtariq@usz.ch 

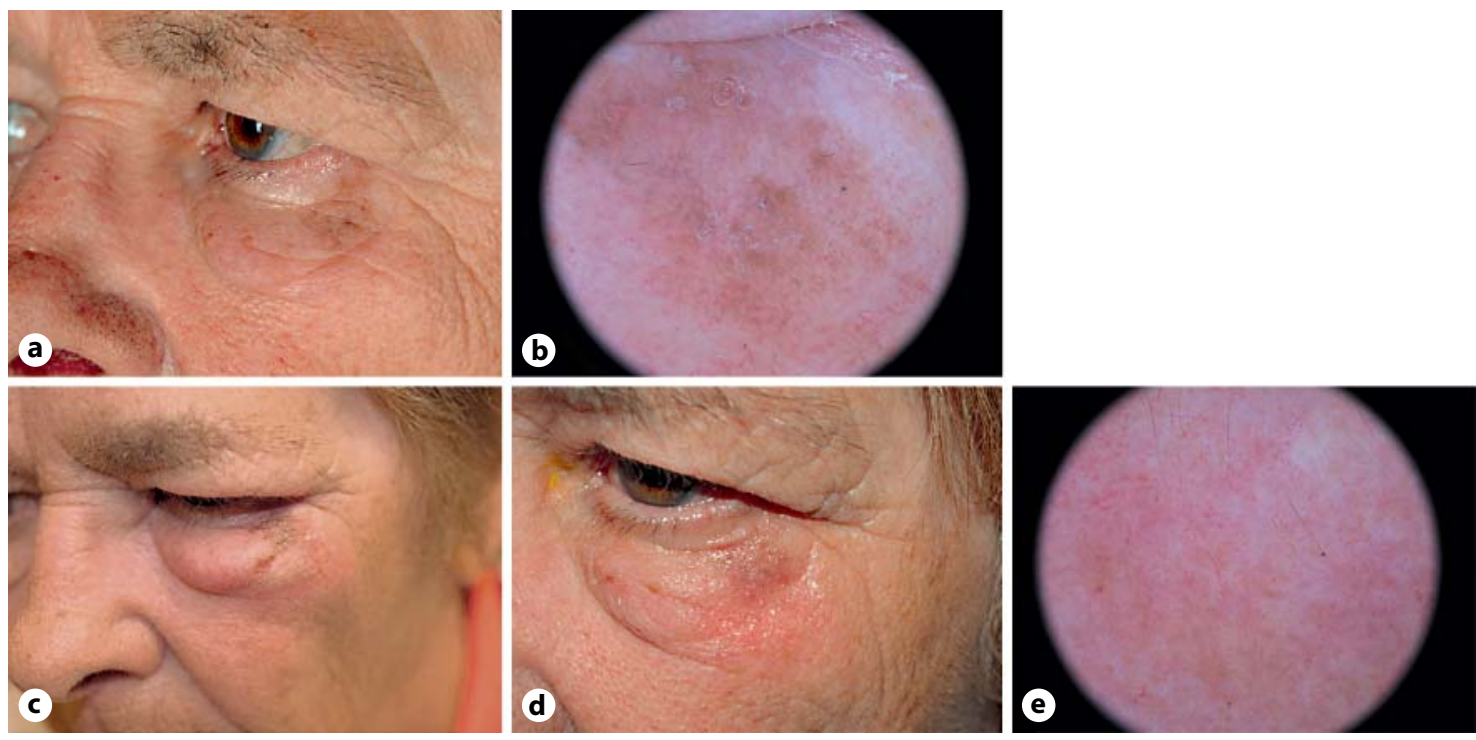

Fig. 1. a A brown macule at the lateral corner of the left eye was histologically confirmed as bowenoid AK. b Dermatoscopic picture of the lesion shows hyperkeratosis, brown pigmentation and focal peppering with telangiectasia. c A pronounced local skin reaction around the left eye with erythema and erosion formed after

applying $150 \mu \mathrm{g}$ IM for 3 consecutive days. d A marked improvement of pigmented $\mathrm{AK}$, without infiltration, but a remaining erythema at 2 weeks after IM. e Dermatoscopic picture after IM shows a disappearing of the hyperkeratosis, pigmentation and peppering with telangiectasia.
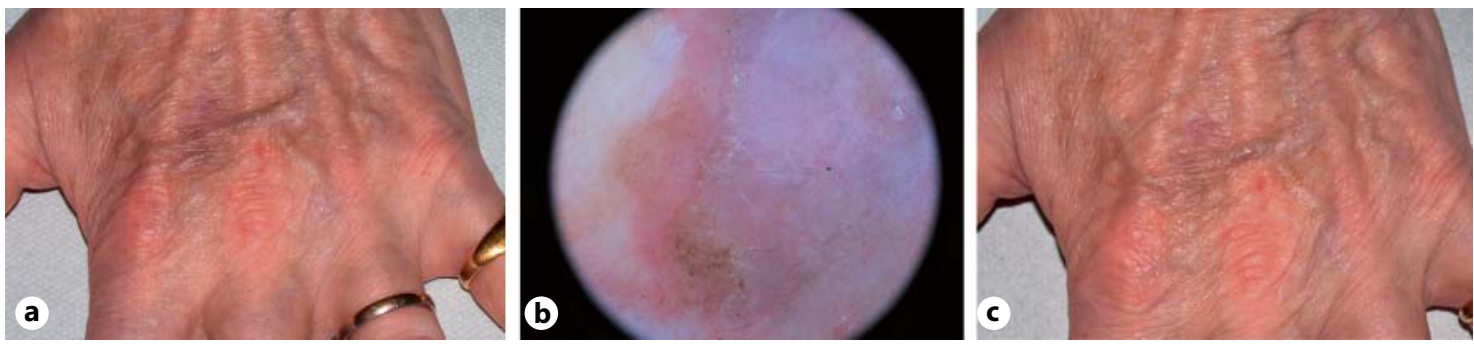

Fig. 2. a Two centimeters hyperkeratotic brown-red plaque on the dorsum of left hand. b Dermatoscopic picture of the lesion shows a pseudo-network, superficial scales and dotted vessels. c A post-inflammatory macule after treatment using $500 \mu \mathrm{g}$ IM for 2 consequence days with clinical remission at 6 weeks.

agulation and desiccation and cryosurgery are accepted ablative treatment options [2]. Therapeutic alternatives to surgery include PDT [3], radiotherapy and topical treatments such as 5-fluorouracil and IQ [4]. Most topical pharmacotherapies induce inflammation with long application period ranging from weeks to months. IM is an active compound in the sap of Euphorbia peplus and has 2 mechanisms of action, including necrosis within hours and cellular cytotoxicity within days, making it a very rapid topical treatment modality $[1,5]$. IM has been registered in the United States, the European Union and in Switzerland as a treatment for AK since 2012 [5]. One advantage of using IM is the short treating course, which could improve patient compliance $[1,4,5]$. A clinical study with Euphorbia peplus sap with an active ingredient IM (PEP005) showed that the effectiveness of IM is not limited to superficial AK only but also extends to clinical healing of IEC in $94 \%$ of patients studied [1]. A case reported was published in September 2014 on successful treatment of multiple BD by IM in a patient on systemic treatment with the multikinase inhibitor sunitinib for metastatic clear-cell renal carcinoma [6]. In our case, the same treatment regimen of AK using IM was applied and led to a successful clinical improvement and remission with high patient satisfaction.

In conclusion, IM could be a useful topical treatment option off-label for patients with BD or hypertrophic, hyperkeratotic AK with the hallmarks of short duration and easy self-application. 


\section{Statement of Ethics}

We do not have the patients' consent since they were treated more than 2-3 years ago, and in one case there was no follow-up.

\section{Disclosure Statement}

The publication costs of this report were financially supported by LEO Pharma.

\section{References}

1 Ramsay JR, Suhrbier A, Aylward JH, Ogbourne S, Cozzi SJ, Poulsen MG, Baumann KC, Welburn P, Redlich GL, Parsons PG: The sap from Euphorbia peplus is effective against human nonmelanoma skin cancers. Br J Dermatol 2011;164:633-636.

2 Micali G, Lacarrubba F, Nasca MR, Ferraro S, Schwartz RA: Topical pharmacotherapy for skin cancer: part II. Clinical applications. J Am Acad Dermatol 2014;70:979.e1-e12; quiz 9912.
3 Westers-Attema A, Lohman BG, van den Heijkant F, Nelemans PJ, Winnepenninckx VJ, Kelleners-Smeets NW, Mosterd K: Photodynamic therapy in Bowen's disease: influence of histological features and clinical characteristics on its success. Dermatology 2015; 230:55-61.

4 Lucena SR, Salazar N, Gracia-Cazaña T, Zamarrón A, González S, Juarranz Á, Gilaberte $Y$ : Combined treatments with photodynamic therapy for non-melanoma skin cancer. Int J Mol Sci 2015;16:25912-25933.

5 Mohanna M, Hofbauer G: Pronounced local skin reaction to ingenol mebutate against actinic keratosis in kidney transplant recipient without systemic adverse events. JAAD Case Rep 2015;1:S19-S22.

6 Braun SA, Homey B, Gerber PA: [Successful treatment of Bowen disease with ingenol mebutate]. Hautarzt 2014;65:848-850. 